\title{
Effect of a community-based pedestrian injury prevention program on driver yielding behavior at marked crosswalks
}

\author{
Laura S. Sandt ${ }^{\mathrm{a}, *}$, Stephen W. Marshall ${ }^{\mathrm{b}}$, Daniel A. Rodriguez ${ }^{\mathrm{c}}$, Kelly R. Evenson ${ }^{\mathrm{d}}$, \\ Susan T. Ennett ${ }^{\mathrm{e}}$, Whitney R. Robinson ${ }^{\mathrm{f}}$ \\ a UNC Highway Safety Research Center, 730 MLK, Jr. Blvd., Ste 300, CB\#3430, Chapel Hill, NC 27599-3430, United States \\ b Department of Epidemiology, Injury Prevention Research Center, University of North Carolina, CVS Bldg., Ste 500, CB\# 7505, Chapel Hill, NC 27599-7505, \\ United States \\ c Department of City and Regional Planning, University of California, Berkeley, 230 Wurster Hall \#1820, Berkeley, CA 94720-1820, United States \\ d Department of Epidemiology, University of North Carolina, CVS Bldg., Ste 306, CB\# 8050, Chapel Hill, NC 27599-8050, United States \\ e Department of Health Behavior, University of North Carolina, 358A Rosenau Hall, CB\#7440, Chapel Hill, NC 27599-7440, United States \\ ${ }^{f}$ Department of Epidemiology, University of North Carolina, 2104B McGavran-Greenberg Hall, CB\# 7435, Chapel Hill, NC 27599-7435, United States
}

\section{A R T I C L E I N F O}

\section{Article history:}

Received 28 November 2015

Received in revised form 19 March 2016

Accepted 3 May 2016

Available online 18 May 2016

\section{Keywords:}

Pedestrian

Enforcement

Intervention

Evaluation

Driver

Yield

\begin{abstract}
A B S T R A C T
Background: Few studies have comprehensively evaluated the effectiveness of multi-faceted interventions intended to improve pedestrian safety. "Watch for Me NC" is a multi-faceted, community-based pedestrian safety program that includes widespread media and public engagement in combination with enhanced law enforcement activities (i.e., police outreach and targeted pedestrian safety operations conducted at marked crosswalks) and low-cost engineering improvements at selected crossings. The purpose of this study was to estimate the effect of the law enforcement and engineering improvement components of the program on motor vehicle driver behavior, specifically in terms of increased driver yielding to pedestrians in marked crosswalks.

Methods: The study used a pre-post design with a control group, comparing crossing locations receiving enforcement and low-cost engineering treatments (enhanced locations) with locations that did not (standard locations) to examine changes in driver yielding over a 6-month period from 2013 to 2014. A total of 24,941 drivers were observed in 11,817 attempted crossing events at 16 crosswalks in five municipalities that were participating in the program. Observations of real pedestrians attempting to use the crosswalks ("naturalistic" crossing) were supplemented by observations of trained research staff attempting the same crossings following an established protocol ("staged" crossings). Generalized estimating equations (GEE) were used to model driver yielding rates, accounting for repeated observations at the crossing locations and controlling other factors that affect driver behavior in yielding to pedestrians in marked crosswalks.

Results: At crossings that did not receive enhancements (targeted police operations or low-cost engineering improvements), driver yielding rates did not change from before to after the Watch for Me NC program. However, yielding rates improved significantly (between 4 and 7 percentage points on average) at the enhanced locations. This was true for both naturalistic and staged crossings.

Conclusions: This study provides evidence that enhanced enforcement and low-cost engineering improvements, as a part of a broader program involving community-based outreach, can increase driver yielding to pedestrians in marked crosswalks. These data are important for the staff and decision-makers involved in pedestrian safety programs to gain a better understanding of the different engineering and behavioral mechanisms that could be used to improve driver yielding rates.
\end{abstract}

Published by Elsevier Ltd.

* Corresponding author.

E-mail addresses: sandt@hsrc.unc.edu (L.S. Sandt), smarshall@unc.edu (S.W. Marshall), daniel.a.rodriguez.pinzon@gmail.com (D.A. Rodriguez), kelly_evenson@unc.edu (K.R. Evenson), sennett@email.unc.edu (S.T. Ennett), whitney_robinson@unc.edu (W.R. Robinson). 


\section{Introduction}

Injury, and in particular traffic-related injury, is a leading cause of morbidity and disability, resulting in a substantial loss of productive years and accounting for a considerable cost to the U.S. health system (Finkelstein et al., 2006). In both the U.S. and North Carolina (NC), pedestrians represent more than $13 \%$ of all motor vehicle crash (MVC) fatalities occurring on public roadways. According to the latest data available from the National Highway Traffic Safety Administration, 4743 pedestrians were killed in MVCs in the U.S. in 2012 , and another 76,000 pedestrians were injured (National Highway Traffic Safety Administration, 2014). In NC, there are 2200 pedestrian-involved MVCs each year, resulting in between 150 and 200 pedestrian deaths and an additional 500 serious injuries (University of North Carolina, 2011). The Centers for Disease Control and Prevention (CDC) has recognized transportation-related injuries as one of public health's "winnable battles," and has identified pedestrian safety as a primary research area within transportation safety (Centers for Disease Control and Prevention (CDC), 2009).

A key injury research priority in the area of pedestrian safety is to evaluate the effectiveness of multifaceted strategies (e.g., those involving education/outreach, law enforcement, and changes to the built environment) to prevent pedestrian injuries (Centers for Disease Control and Prevention (CDC), 2009). Such research is needed to understand the effectiveness of pedestrian interventions and assist localities in planning and implementing such programs. However, to date there is limited research available that quantifies the effectiveness of multifaceted community-based pedestrian injury prevention interventions.

\subsection{Prior research}

Few evaluations of community-based pedestrian safety programs have been conducted using pedestrian injuries and/or crashes as the outcome. Most studies have examined the outcome of driver behavior, such as compliance with laws requiring that drivers yield (give way) to pedestrians using marked crosswalk ("yielding laws"). Only a handful of studies (described below) have evaluated the impact of multifaceted pedestrian safety interventions on behavioral driver outcomes, and the results from these studies have been mixed.

In an evaluation of an intervention involving law enforcement, engineering improvements, and a public information campaign in Shoreline, WA from 1999 to 2003, researchers used observations at two locations (with no control locations)(Nee and Hallenbeck, 2003 ) to quantify pedestrian crossing behaviors and driver yielding behaviors before and after the intervention. Driver yielding increased from $0 \%$ to $17-70 \%$, likely due to the significant package of roadway improvements and pedestrian crossing facilities. Driver yielding increased on only one crossing of one intersection following enforcement, but enforcement intensity was noted to be limited.

A repeated measures study of driver behaviors before, during, and after a two-week long enforcement-oriented intervention (supplemented by an education/outreach component) was performed in Miami-Beach, FL (Van Houten and Malenfant, 2004). Unadjusted estimates of the percentage of drivers yielding at eight treated and twelve comparison locations for each measurement wave indicated that driver yielding increased from 3.3\% and $18.2 \%$ at baseline to $27 \%$ and $33.1 \%$ at the two intervention locations, respectively. However, driver yielding at the untreated locations also rose by a similar amount, from $20.5 \%$ to $32.1 \%$, which authors attributed to a spill-over effect of the high-visibility education component.
In Gainesville, FL, researchers randomized enforcement to six of 12 crosswalks and conducted repeated measures of driver and pedestrian behaviors (Van Houten et al., 2013a). Time-series regression models were used to estimate changes in observed driver and pedestrian behavior. Yielding to pedestrians was assessed using staged crossings (pedestrians were members of the research team following a standardized road crossing protocol) and rose from $31.5 \%$ to $62.0 \%$, while yielding to real pedestrians (in naturalistic crossings) rose from $45.4 \%$ to $82.7 \%$. Increases in driver yielding were also observed at crosswalks not targeted for enforcement and changes in yielding were inversely proportional to the distance from the treated crossings, suggesting a potential spill-over treatment effect.

In general, the studies above reported positive associations between the interventions studied and changes in driver yielding, particularly when the intervention used multiple components integrated in a cohesive program. However, the few studies that have used pre/post research designs with control groups typically did not utilize multivariate analysis methods to adjust for potential sources of confounding such as temporal/seasonal factors, time of day, and aspects of the built environment (e.g. crosswalk markings) that may influence driver yielding behavior.

\section{2. "Watch for Me NC" intervention}

In NC, a pedestrian safety intervention, "Watch for Me NC," was developed and implemented with the aim of reducing pedestrian crashes and injuries. Watch for Me NC is a community-based program involving a comprehensive set of education, outreach, and law enforcement measures. A key emphasis was to increase awareness of, and compliance with, laws requiring drivers to yield to pedestrians in marked crosswalks. The program was predicated on the concept that education and enforcement could modify driver and pedestrian behavior and therefore reduce pedestrian crash rates. The main components of the program were: (1) a widespread community-based media and local outreach campaign designed to increase awareness of pedestrian safety and related laws, and (2) a law enforcement program that involved educating police officers about pedestrian traffic laws and assisting them in enhancing pedestrian safety by implementing high-visibility enforcement activities and public outreach at selected crossing locations. "High visibility" enforcement typically involved an extensive effort by police to make the public aware of its enforcement operations, which may have included issuing press releases before or after an operation was conducted, using signs or banners at the location of enforcement, going door to door to alert local residents and business owners of enforcement plans, and other public outreach efforts. Additionally, a small number of low-cost engineering improvements (such as signage and pavement markings) were made at selected crosswalks in the same timeframe as the Watch for Me NC program delivery. A timeline of the Watch for Me NC program is provided in Table 1.

Details on the development and delivery of the Watch for Me NC are described elsewhere and can also be found on the program website, www.WatchforMeNC.org (Sandt et al., 2015).

The aim of this paper was to examine the effect of the enhanced high-visibility enforcement activities and low-cost engineering treatments components of the Watch for Me NC intervention. We hypothesized that driver yielding rates would be higher at the locations receiving enhanced enforcement and other treatments in comparison to the pre-intervention yielding rates at the same locations and the post-intervention yielding rates at "standard" enforcement locations (i.e., comparison locations that did not receive additional law enforcement operations or engineering improvements). 
Table 1

Timeline of Watch for Me NC intervention delivery and evaluation activities.

\begin{tabular}{|c|c|c|}
\hline Timeframe & Intervention Delivery & Intervention Evaluation \\
\hline May 2013-July 2013 & $\begin{array}{l}\text { Watch for Me NC community partners develop education/outreach and } \\
\text { communication plans and receive materials/media and technical assistance }\end{array}$ & $\mathrm{N} / \mathrm{A}$ \\
\hline July 2013-August 2013 & $\begin{array}{l}\text { Law enforcement officers receive training on pedestrian laws and how to } \\
\text { conduct targeted, high visibility operations; departments develop } \\
\text { plans/schedules for conducting operations }\end{array}$ & $\begin{array}{l}\text { Administrative records gathered from } \\
\text { police departments }\end{array}$ \\
\hline August 2013-September 2013 & $\begin{array}{l}\text { Watch for Me NC “educational” activities begin: Kick off events, media } \\
\text { engagement, public meetings, paid media (e.g., radio, transit, and outdoor ads), } \\
\text { material distribution (brochures, posters, safety materials), grassroots } \\
\text { outreach efforts, etc. }\end{array}$ & $\begin{array}{l}\text { "Before" data collected on driver } \\
\text { yielding }\end{array}$ \\
\hline October 2013-February 2014 & $\begin{array}{l}\text { High visibility law enforcement operations take place at select high-crash } \\
\text { locations }\end{array}$ & $\begin{array}{l}\text { "After" data collected on driver } \\
\text { yielding }\end{array}$ \\
\hline October 2013-February 2014 & Low-cost engineering improvements are made at select high-crash locations & $\begin{array}{l}\text { "After" data collected on driver } \\
\text { yielding }\end{array}$ \\
\hline
\end{tabular}

\section{Methods}

This study used a pre-post design with a comparison group to examine the effect of the enhanced enforcement programs at 16 crosswalk locations in five NC municipalities that implemented the Watch for Me NC program from August 2013 to January 2014. Data were collected by 1 ) observing real pedestrians attempting to use the crosswalks under study ("naturalistic" events), and 2) observing a series of staged crossings using trained research staff attempting to cross the road ("staged" events), following an established protocol (Sandt et al., 2014) also used in other studies (Van Houten et al., 2013a).

\subsection{Site selection}

Driver yielding data were collected from August 2013 to January 2014 in five "Triangle region" NC municipalities - Raleigh, Durham, Chapel Hill, Carrboro, and Fuquay-Varina - that were actively participating in the Watch for Me NC pedestrian injury prevention program. In these five cities, 16 crossing locations were selected for data collection based on the following criteria: (1) it was located near an intersection where there was a relatively high pedestrian crash frequency, based on an analysis of five years' of pedestrian crash data, (2) posted speed limit at the crossing was at or below $35 \mathrm{MPH}$, (3) the crossing was uncontrolled (i.e., at an unsignalized intersection or midblock location), (4) the crossing had a marked crosswalk, (5) the crossing experienced adequate pedestrian traffic for conducting naturalistic observations, and (6) site geometry enabled pedestrian enforcement operations to be conducted (e.g., there was sufficient space downstream of the crossing to pull over non-compliant vehicles, etc.). The criteria were not intended to identify a geographically representative sample of crossings, but rather identify a sample of crossings with the appropriate conditions for applying enhanced high-visibility law enforcement and other potential safety interventions.

Crossing locations were not randomly assigned to receive enforcement enhancements. Law enforcement agencies were provided with a set of crossing locations meeting the above criteria and encouraged to perform operations at these or similar locations, but agencies also took into consideration other factors (such as available resources, public complaints, etc.) before deciding which locations would receive enhanced enforcement. The police agencies provided the research team with administrative records regarding the number of targeted pedestrian operations they performed during the study period, as well as location and duration of each operation. Based on this data, eight crossing locations were classified as "standard" and eight were classified as "enhanced." The standard (i.e., comparison) locations were defined as those that did not receive any enhanced enforcement during the intervention period, whereas the "enhanced" (or treated) locations were visited one or more times by officers conducting high-visibility pedestrian safety operations. The standard and enhanced crossings were similar across the key dimensions included in the site selection criteria described above but, as reported below, differed in some other ways. Some of the enhanced crossings also received low-cost engineering treatments during the study period, such as re-striped crosswalks, in-street signs, or rectangular rapid flashing beacons (RRFBs).

\subsection{Data collection - staged E naturalistic crossings}

At each crossing, data collectors observed pedestrian interactions with drivers using specific, well-established protocols, which were also used in similar studies of driver yielding rates (Van Houten et al., 2013a). Observers recorded both "naturalistic" and "staged" pedestrian crossings. Protocols and field-based trainings gave clear guidance on how and when staged crossings should be performed and how to assess and code driver yielding and other behaviors. For example, data collectors were instructed to first define a "dilemma zone" for each crossing (the distance beyond which a driver could easily stop for a pedestrian, based on posted speed limit and other factors). Then they followed specific instructions regarding the type of clothing to wear (neutral colors), where to position themselves in between crossing attempts (so as to not indicate intent to cross to confuse oncoming drivers), how to approach the crossing and communicate with oncoming drivers in a natural but non-aggressive way (making eye contact and putting a foot in the crosswalk to indicate intent but not using hand gestures or stepping fully into the travel lane until it was clear that the driver was yielding), and how/when to attempt a complete crossing. The data collection team timed their approach to the crosswalks so that approaching vehicles were always beyond the dilemma zone, and vehicles already within the dilemma zone (in either direction, if on a two-way street) were not included in counts of cars failing to yield (for staged or natural crossings). For the full protocol, see Appendix E of the Final Agency Report (Sandt et al., 2014).

Staged crossings provided an alternative data stream that allowed us to control for certain parameters, including pedestrian volumes and the pre-crossing behaviors mentioned above, and achieve a higher sampling of pedestrian-driver interactions given the time available for data collection. Staged crossing were a particularly efficient means of collecting data at lower pedestrian volume locations. For both types of crossings, several quality assurance and control measures were put in place to ensure consistent data collection. These included a three-part training program for the data collectors, involving the provision of written protocols, in-class 


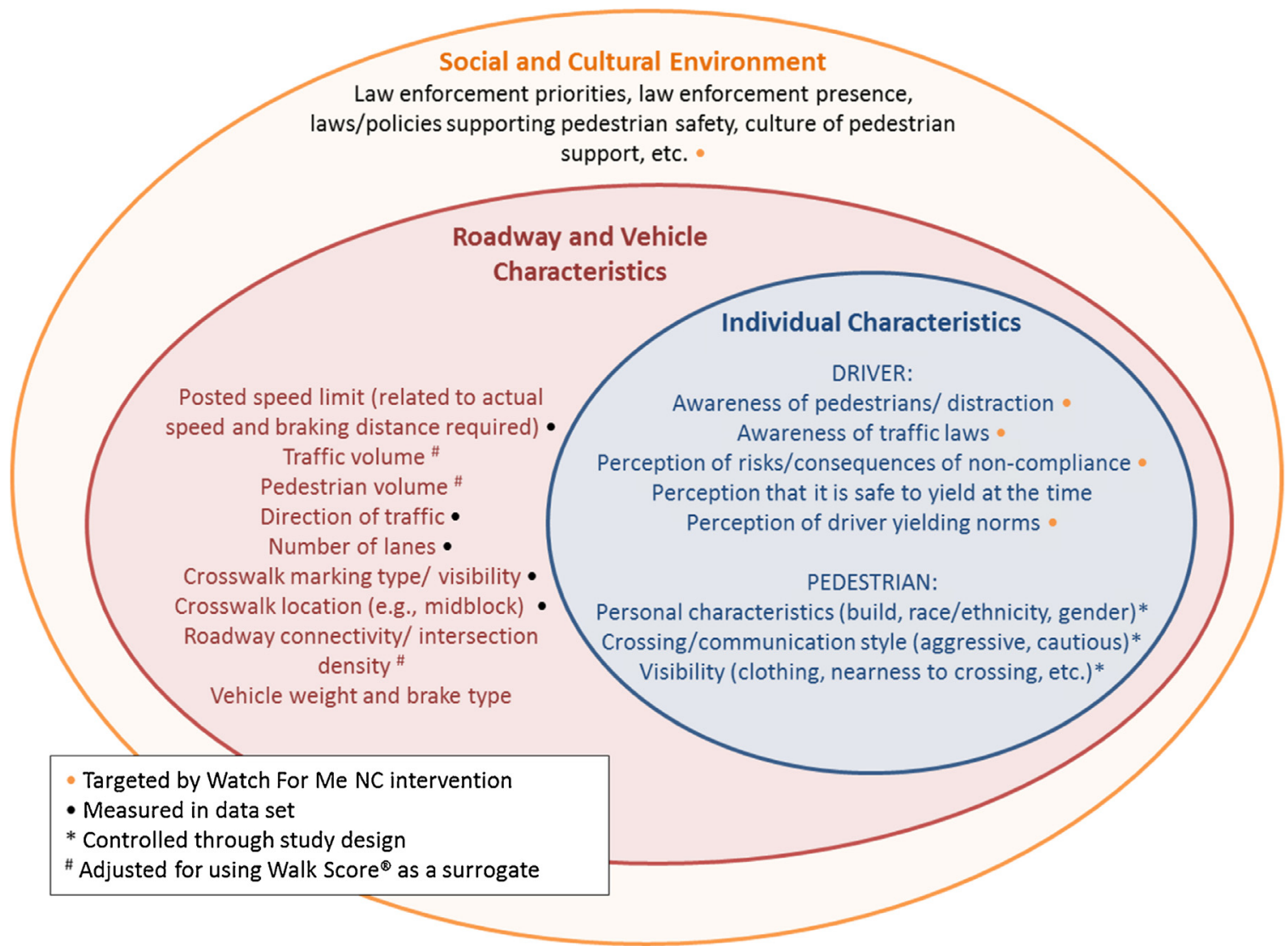

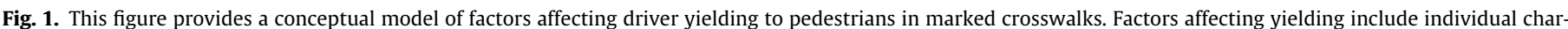

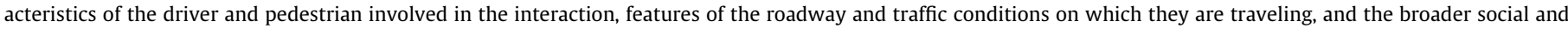
cultural environment. Several of these factors were measured directly or indirectly in the study and used in the adjusted models (Models 2 and 3 ).

training with visual examples and crossing scenarios, and extensive field-based practice at actual data collection locations. It also included routine, weekly checks on the data collector operations to confirm fidelity to protocols and personal review of the data to check for inaccuracies and inconsistencies in data coding.
For safety reasons, data were collected only on dry-weather weekdays during daylight hours, and the team did not collect data during times when engineering enhancements were being made. Each crosswalk location was visited 10-12 times with roughly half of the visits "pre-intervention" and half in the postintervention period. The "pre-intervention" period was defined as

Table 2

Characteristics of standard (comparison) crossing locations where driver yielding data was collected from 2013 to 2014 in five North Carolina municipalities.

\begin{tabular}{|c|c|c|c|c|c|c|c|c|}
\hline Location & Crossing Type & $\begin{array}{l}\text { Crosswalk } \\
\text { Markings }\end{array}$ & $\begin{array}{l}\text { Posted Speed } \\
\text { Limit }\end{array}$ & Total \# of Lanes & $\begin{array}{l}\text { Direction of } \\
\text { Traffic }\end{array}$ & Walk Score ${ }^{\circledR}$ & $\begin{array}{l}\text { Total \# of } \\
\text { pedestrian } \\
\text { crossing } \\
\text { attempts made } \\
\text { or observed }\end{array}$ & $\begin{array}{l}\text { Total \# of Cars } \\
\text { Observed }\end{array}$ \\
\hline C-Greensboro & Midblock & Standard & $20 \mathrm{MPH}$ & 2 & Two-way & 86 & 779 & 1282 \\
\hline D-Anderson & $\begin{array}{l}\text { Uncontrolled } \\
\text { Intersection }\end{array}$ & Standard & $25 \mathrm{MPH}$ & 2 & Two-way & 56 & 629 & 1550 \\
\hline D-Main & Midblock & High Visibility & $25 \mathrm{MPH}$ & $2+$ median & Two-way & 83 & 689 & 1067 \\
\hline D-Tobacco & $\begin{array}{l}\text { Midblock trail } \\
\text { crossing with } \\
\text { beacon }\end{array}$ & High Visibility & $35 \mathrm{MPH}$ & 2 & Two-way & 26 & 630 & 2017 \\
\hline R-Blount & Midblock & High Visibility & $\begin{array}{l}\text { Not posted; } \\
\text { assume } 35 \mathrm{MPH}\end{array}$ & 3 & One-way & 96 & 764 & 2213 \\
\hline R-Capitol & Midblock & High Visibility & $\begin{array}{l}\text { Not posted; } \\
\text { assume } 35 \mathrm{MPH}\end{array}$ & 3 & One-way & 93 & 632 & 1802 \\
\hline R-South & Midblock & High Visibility & $25 \mathrm{MPH}$ & 3 & Two-way & 86 & 492 & 837 \\
\hline R-Wilmington & Midblock & High Visibility & $\begin{array}{l}\text { Not posted; } \\
\text { assume } 35 \mathrm{MPH}\end{array}$ & 2 & One-way & 93 & 855 & 1675 \\
\hline
\end{tabular}

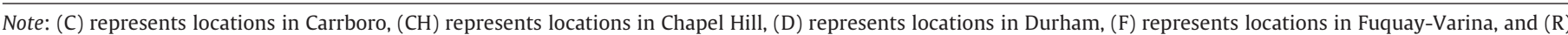
represents locations in Raleigh. 
August and September 2013, before the enforcement and engineering elements of the campaign were in place but after the general education and public education elements were conducted. The "post-intervention" period consisted of data collected from October 1, 2013 through the end of February 2014.

Although weather-dependent, the data collection schedule aimed for consistency in the time of day and the day of week that each location was visited to help control for environmental effects. Both staged and naturalistic crossings were observed during each visit to each crossing location to minimize differences in the conditions in which the two types of crossing data were collected. Similarly, while data collection schedules occasionally had to be modified due to illness or personal schedules, the plan consistently used the same two primary data collectors from August 2013 to February 2014 to limit confounding due to individual differences in data collection or crossing behaviors. Inter-observer agreement of estimated driver yielding rates differed by less than $5 \%$ and there were no systemic differences in the coding of yielding behavior.

\subsection{Statistical analysis}

Linear risk models (identity link, binomial residual) were developed to estimate crude and adjusted driver yielding rates, 95\% confidence intervals, and $p$-values. Driver yielding rates were calculated using the total number of vehicles that yielded to pedestrians that attempted a crossing (which could have been more than one vehicle if there were multiple lanes of traffic to cross) over the total number of vehicles observed during the interaction (which included the yielding vehicles plus the vehicles approaching the crossing that could have yielded, based on their location relative to the dilemma zone, but did not). Models were fit for the naturalistic and staged crossings separately. Generalized estimating equations (GEE) with robust ("sandwich") standard errors were used to account for within-site correlation induced by making repeated observations at the same crossing locations (Stokes et al., 2000). An independence specification was used for the GEE working correlation matrix. Upon initial inspection of the data, crossings at two standard locations (D-Tobacco and R-South) and one enhanced location (C-Hillsborough) had less than 50 naturalistic crossing events observed; these locations were removed from the naturalistic crossing analysis because there were too few observations to reliably estimate effects at these locations. Therefore the naturalistic analyses were limited to 13 locations, whereas staged analyses used data from all 16 locations. Regression diagnostics were used to identify potential violations of model assumptions, and goodness of fit statistics were examined using the QIC and QI Cu statistics.

A "base" unadjusted model was used to estimate unadjusted effects (Model 1). This model included only terms for the intervention group (enhanced locations vs. standard locations), time (i.e., pre/post Watch for Me NC intervention), and the time by group interaction.

An "adjusted" model (Model 2) included selected measured covariates from a wide range of covariates thought to impact driver yielding based on a conceptual model (Fig. 1). This model adjusted for: time of day (afternoon vs morning), commute time (peak vs off-peak), crossing location (uncontrolled intersection vs midblock crossing), crosswalk marking type (standard parallel lines vs high-visibility "continental" style), direction of traffic (one-way vs two-way), number of traffic lanes (two-lane vs 3+ lane), posted speed limit ( $<30 \mathrm{MPH}$ vs $30+\mathrm{MPH})$, and city population $(<60 \mathrm{~K}$ or $<=60 \mathrm{~K}$ ). An examination of collinearity was undertaken but none was detected.

A third model (Model 3) sought to explore and adjust for additional built environment factors that might influence driver or pedestrian behavior, while including a more parsimonious set of covariates. Specifically, the Street Smart Walk Score ${ }^{\circledR}$ (www.

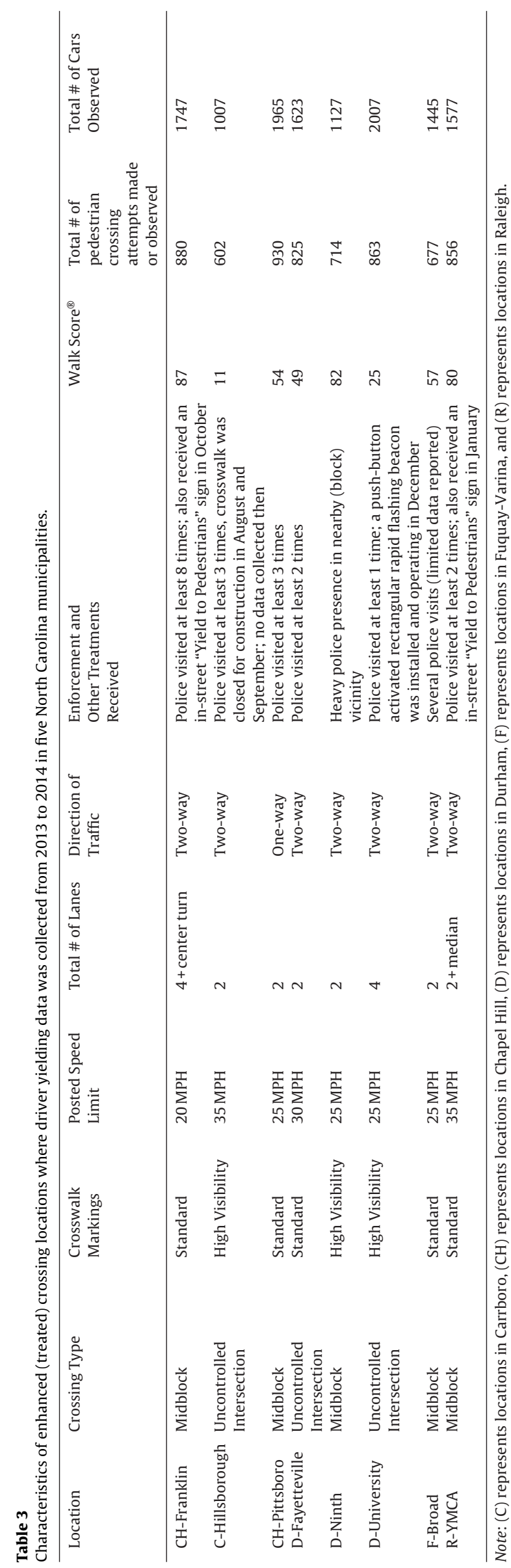


walkscore.com, heretofore referred to as "Walk Score ${ }^{\circledR}$ ") was used as a marker of area "walkability." Walk Score ${ }^{\circledR}$ is an indicator of the built environment's supportiveness of walkability on a scale from 0 to 100 , with higher numbers representing higher walkability. The Walk Score ${ }^{\circledR}$ combines information on distance to destinations accessible from the crossing location, with weighting based on the importance of destinations to walking. Walk Scores ${ }^{\circledR}$ are then adjusted for street network characteristics so that places with low intersection density (or poor roadway connectivity) and longer block lengths received lower scores. Destinations (i.e., grocery stores, schools, parks, restaurants, and retail), intersection density, and block length each have been associated with walking in other studies (Hirsch et al., 2013). It was hypothesized that the Walk Score ${ }^{\circledR}$ variable was a marker of potential pedestrian and automobile volume, as indicated in the conceptual model in Fig. 1. Walk Scores ${ }^{\circledR}$ were obtained for the 16 crossing locations and for each municipality as a whole. These two continuous variables were examined in relation to driver yielding rates and to other covariates before being added to the model. The Walk Scores ${ }^{\circledR}$ were found to be strongly correlated with several other variables (including crossing location, direction of traffic, and number of lanes); these variables were removed from Model 3 in favor of the Walk Score ${ }^{\circledR}$ variable to improve model stability and interpretation. The crossing-location specific Walk Score ${ }^{\circledR}$ was centered on the city average Walk Scores ${ }^{\circledR}$, which was rescaled to support a meaningful interpretation of the intercept term.

\section{Results}

\subsection{Standard and enhanced locations}

A total of 24,941 drivers were observed in 11,817 pedestrian and motor vehicle crossing interactions (3397 natural and 8420 staged) observed at the 16 crossing locations. Tables 2 and 3 summarize characteristics of the standard and enhanced data collection locations. Collectively, the standard locations have very similar physical characteristics (such as speed limit, land uses, crosswalk type, etc.) as the enhanced locations. However, there were some notable differences, such as the larger proportion of crosswalks with high visibility markings and higher Walk Scores for the standard locations compared to the enhanced locations. These differences underscore why the project team adjusted for these variables in Model 2 and undertook an examination of potential covariates and modifiers, described in the following sections.

\subsection{Intervention effects}

For staged pedestrian crossings at enhanced locations, average driver yielding rates improved $6.9 \%$ points, from a rate of $40.7 \%$ before the enforcement and low-cost engineering (if any) components to $47.6 \%$ afterward, a statistically significant difference (see Table 4). Similarly, for naturalistic crossings observed at the enhanced locations, driver yielding rates improved $4.3 \%$ points (statistically significant at alpha $=0.05$ ), from a rate of $51.1 \%$ before to $55.4 \%$. In contrast, driver yielding at the standard crossing locations remained similar from before to after the intervention (from 28.8 to $29.8 \%$ for staged crossings, and from 39.3 to $41.3 \%$ for naturalistic crossings; neither increase was statistically significant). While baseline yielding rates and changes in yielding varied by location, five of the eight enhanced locations saw positive increases in driver yielding, ranging from a 7.2 to a $17.0 \%$ point difference. At standard enforcement locations, changes in driver yielding rates ranged from $-7.3 \%$ to $8.4 \%$.

As detailed above, the decision regarding which of the 16 locations received enhanced treatment was not random, but was determined by the local enforcement staff and was therefore outside of the control of the research team. Thus the distribution of predictive covariates across study arms was not at random and between-site differences in covariate values/distributions were a potential source of confounding bias. For example, standard locations were all in larger population cities (with the exception of one crossing) compared to the enhanced locations. Also, the standard crossing locations had more high visibility crosswalk markings than the enhanced locations (Tables 2 and 3). Models 2 and 3 adjusted for these and other covariates. The estimates of pre/post yielding rate differences were fairly robust across the base and fully-adjusted models: the change in the percentage of drivers yielding to pedestrians (both staged and natural) in the two adjusted models (Model 2 and Model 3) was very similar to the unadjusted Model 1 results (Table 4).

\subsection{Effect of covariates}

Some of the covariates included in Models 2 and 3 were found to have strong associations with driver yielding rates. In particular, high visibility crosswalk markings, crosswalks spanning fewer than three lanes, crossings on low-speed roads (i.e., posted speed limits of less than $30 \mathrm{MPH}$ ), and crossings in smaller communities (less than 60,000 in population) were all associated with higher rates of driver yielding (Table 5).

Similarly, in Model 3 (which included the Walk Score ${ }^{\circledR}$ variable), posted speed limit, crosswalk type, and city size showed associations with driver yielding of a similar direction and magnitude for both staged and natural crossings. The relationship between driver yielding rates and Walk Score ${ }^{\circledR}$ at the crossing or city level varied across naturalistic and staged crossing types and were not statistically significant. Main effects of the intervention were largely unaffected by adjustment for the covariates in Model 3 (Table 4).

Table 4

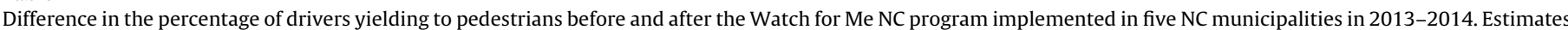
from unadjusted and adjusted models are shown separately for staged and naturalistic crossings conducted at standard and enhanced locations.

\begin{tabular}{|c|c|c|c|c|c|c|}
\hline & \multicolumn{6}{|c|}{ Changes in Driver Yielding Rate, $(95 \% \mathrm{CI})$, and $p$-value } \\
\hline & \multicolumn{2}{|c|}{ Unadjusted (Model 1)a } & \multicolumn{2}{|l|}{ Model $2^{b}$} & \multicolumn{2}{|l|}{ Model $3^{c}$} \\
\hline & Staged $^{\mathrm{d}}$ & Naturalistic $^{\mathrm{e}}$ & Staged $^{\mathrm{d}}$ & Naturalistic $^{e}$ & Staged $^{\mathrm{d}}$ & Naturalistic $^{e}$ \\
\hline Standard locations & $\begin{array}{l}1.0 \%(-4.2,6.2) \\
p=0.70\end{array}$ & $\begin{array}{l}2.0 \%(-0.9,4.9) \\
p=0.18\end{array}$ & $\begin{array}{l}0.9 \%(-3.5,5.3) \\
p=0.69\end{array}$ & $\begin{array}{l}1.5 \%(-1.5,4.5) \\
p=0.33\end{array}$ & $\begin{array}{l}2.4 \%(1.3,6.0) \\
p=0.20\end{array}$ & $\begin{array}{l}2.2 \%(-1.7,6.0) \\
p=0.26\end{array}$ \\
\hline Enhanced locations & $\begin{array}{l}6.9 \%(1.3,12.5) \\
p=0.01\end{array}$ & $\begin{array}{l}4.3 \%(0.2,8.5) \\
p=0.04\end{array}$ & $\begin{array}{l}6.4 \%(1.6,11.2) \\
p=0.01\end{array}$ & $\begin{array}{l}3.8 \%(0.4,7.2) \\
p=0.02\end{array}$ & $\begin{array}{l}6.6 \%(1.5,11.8) \\
p=0.01\end{array}$ & $\begin{array}{l}4.4 \%(0.5,7.7) \\
p=0.03\end{array}$ \\
\hline
\end{tabular}

\footnotetext{
a Linear binomial GEE model with terms for treatment, time period, and interaction.

b Linear binomial GEE model adjusted for covariates in Table 5.

c Linear binomial GEE model adjusted for Walk Score, time of day, marking type, speed limit, and city population.

d $\mathrm{n}=16$ locations for staged crossings.

e $\mathrm{n}=13$ locations for naturalistic crossings.
} 
Table 5

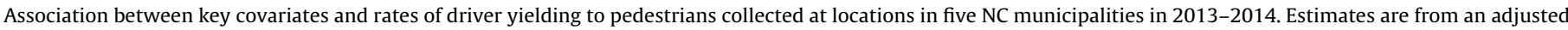
model (Model 2) and are shown separately for staged and naturalistic crossings.

\begin{tabular}{|c|c|c|c|c|c|c|}
\hline \multirow[t]{2}{*}{ Covariate } & \multicolumn{3}{|c|}{ Staged Crossings ( $\mathrm{n}=16$ locations) } & \multicolumn{3}{|c|}{ Naturalistic Crossings ( $\mathrm{n}=13$ locations) } \\
\hline & $\begin{array}{l}\mathrm{N} \\
\text { Yielded }\end{array}$ & $\begin{array}{l}\mathrm{N} \\
\text { Observed }\end{array}$ & $\begin{array}{l}\text { Difference in Driver } \\
\text { Yielding Rate }(95 \% \mathrm{CI}) \\
\text { and } p \text {-value }\end{array}$ & $\begin{array}{l}\mathrm{N} \\
\text { Yielded }\end{array}$ & $\begin{array}{l}\mathrm{N} \\
\text { Observed }\end{array}$ & $\begin{array}{l}\text { Difference in Driver } \\
\text { Yielding Rate }(95 \% \mathrm{CI}) \\
\text { and } p \text {-value }\end{array}$ \\
\hline City Population & & & & & & \\
\hline $\begin{array}{l}<60 \mathrm{~K} \\
>=60 \mathrm{~K}\end{array}$ & $\begin{array}{l}2959 \\
3936\end{array}$ & $\begin{array}{l}5500 \\
13,214\end{array}$ & $\begin{array}{l}19.6 \%(10.6,28.6) p<0.01 \\
\text { Ref }\end{array}$ & $\begin{array}{l}1211 \\
1612\end{array}$ & $\begin{array}{l}1848 \\
4002\end{array}$ & $\begin{array}{l}43.5 \%(18.4,68.6) p<0.01 \\
\text { Ref }\end{array}$ \\
\hline $\begin{array}{l}\text { Crossing Type } \\
\text { Uncon'd inter. } \\
\text { Midblock }\end{array}$ & $\begin{array}{l}1662 \\
5233\end{array}$ & $\begin{array}{l}4658 \\
14,056\end{array}$ & $\begin{array}{l}-1.9 \%(-9.2,5.4) p=0.61 \\
\text { Ref }\end{array}$ & $\begin{array}{l}658 \\
2165\end{array}$ & $\begin{array}{l}1431 \\
4419\end{array}$ & $\begin{array}{l}10.2 \%(-0.0,20.5) p=0.05 \\
\text { Ref }\end{array}$ \\
\hline $\begin{array}{c}\text { Time of Day } \\
\text { Afternoon } \\
\text { Morning }\end{array}$ & $\begin{array}{l}3360 \\
3535\end{array}$ & $\begin{array}{l}9022 \\
9692\end{array}$ & $\begin{array}{l}-3.2 \%(-10.5,4.1) p=0.39 \\
\text { Ref }\end{array}$ & $\begin{array}{l}1019 \\
1804\end{array}$ & $\begin{array}{l}2337 \\
3513\end{array}$ & $\begin{array}{l}-1.1 \%(-9.5,7.3) p=0.80 \\
\text { Ref }\end{array}$ \\
\hline $\begin{array}{l}\text { Rush Hour } \\
\text { Peak } \\
\text { Off-Peak }\end{array}$ & $\begin{array}{l}3260 \\
3635\end{array}$ & $\begin{array}{l}10,039 \\
8675\end{array}$ & $\begin{array}{l}-5.9 \%(-11.5,0.4) p=0.04 \\
\text { Ref }\end{array}$ & $\begin{array}{l}1235 \\
1588\end{array}$ & $\begin{array}{l}2346 \\
3504\end{array}$ & $\begin{array}{l}9.2 \%(-0.8,19.3) p=0.07 \\
\text { Ref }\end{array}$ \\
\hline $\begin{array}{l}\text { Marking Type } \\
\text { Standard } \\
\text { High Vis. }\end{array}$ & $\begin{array}{l}3560 \\
3335\end{array}$ & $\begin{array}{l}10,743 \\
7971\end{array}$ & $\begin{array}{l}-13.5 \%(-20.0,-7.1) p<0.01 \\
\text { Ref }\end{array}$ & $\begin{array}{l}1164 \\
1659\end{array}$ & $\begin{array}{l}2632 \\
3218\end{array}$ & $\begin{array}{l}-30.2 \%(-46.8,-13.6) p<0.01 \\
\text { Ref }\end{array}$ \\
\hline $\begin{array}{c}\text { Speed Limit } \\
\text { <30 MPH } \\
30 \mathrm{MPH}+\end{array}$ & $\begin{array}{l}4323 \\
2572\end{array}$ & $\begin{array}{l}9783 \\
8931\end{array}$ & $\begin{array}{l}9.2 \%(1.9,16.4) p=0.01 \\
\text { Ref }\end{array}$ & $\begin{array}{l}1944 \\
879\end{array}$ & $\begin{array}{l}3221 \\
2629\end{array}$ & $\begin{array}{l}3.6 \%(-12.4,19.7) p=0.66 \\
\text { Ref }\end{array}$ \\
\hline $\begin{array}{l}\text { \# of Lanes } \\
2 \\
3+\end{array}$ & $\begin{array}{l}4999 \\
1896\end{array}$ & $\begin{array}{l}12,242 \\
6472\end{array}$ & $\begin{array}{l}11.9 \%(7.2,16.5) p<0.01 \\
\text { Ref }\end{array}$ & $\begin{array}{l}1853 \\
970\end{array}$ & $\begin{array}{l}3739 \\
2111\end{array}$ & $\begin{array}{l}12.9 \%(4.8,21.0) p<0.01 \\
\text { Ref }\end{array}$ \\
\hline $\begin{array}{l}\text { Traffic Dir. } \\
\text { One-Way } \\
\text { Two-Way }\end{array}$ & $\begin{array}{l}1696 \\
5199\end{array}$ & $\begin{array}{l}5414 \\
13,300\end{array}$ & $\begin{array}{l}-0.80 \%(-11.3,9.7) p=0.88 \\
\text { Ref }\end{array}$ & $\begin{array}{l}1050 \\
1773\end{array}$ & $\begin{array}{l}2241 \\
3609\end{array}$ & $\begin{array}{l}-4.0 \%(-17.6,9.7) p=0.57 \\
\text { Ref }\end{array}$ \\
\hline
\end{tabular}

Note: Effects are adjusted for all other variables in this table based on a linear binomial GEE model with terms for treatment, time period, and interaction.

\subsection{Modifiers of intervention effects}

Table $6 \mathrm{a}$ and $6 \mathrm{~b}$ compares changes in unadjusted driver yielding rates between standard and enhanced locations, stratified by key covariates. The goal of these analyses was to determine if the intervention effect was stronger (by more than $10 \%$ ) in specific strata of any of the covariates. In the staged crossing data, we found a greater effect of enforcement on driver yielding behavior at locations with high visibility crosswalk markings. In the naturalistic crossing data, we saw a greater effect of enforcement at crossings located at an uncontrolled intersection (rather than a midblock location) and when crossings took place in the morning and/or during rush hour.

These tables also highlight the higher rate of baseline (pre-WFM) yielding at many of the enhanced locations compared to the standard locations, a pre-existing difference (further explored in the discussion) that made controlling for these covariates necessary.

\section{Discussion}

In comparison to standard locations, modest but important changes in driver yielding, both to real and "staged" pedestrians, were observed at locations receiving enhanced treatment (law enforcement and some low-cost engineering improvements). These modest improvements in driver yielding at the enhanced locations, ranging from 4 to $7 \%$ point improvements, are consistent with the findings of other studies (Van Houten and Malenfant, 2004; Van Houten et al., 2013a), which have found improvement of similar magnitude and direction. As is common in intervention studies, several other covariates showed a more powerful influence on our outcome measure of driver yielding behavior than our intervention.

In general, driver yielding rates involving staged pedestrians were slightly lower than driver yielding rates to observed pedes- trians (in both the before and after periods). It has been suggested (Van Houten and Malenfant, 2004; Van Houten et al., 2013a) that typical pedestrians may be more assertive in indicating their intent to cross (e.g., through hand gesturing and/or stepping into the path of oncoming vehicles before the driver has shown an intent to yield) than "staged" pedestrians, who are members of the research team following protocols for data collection that require a more conservative approach for safety reasons. The estimated effect of the intervention and other covariates on driver yielding were generally similar for staged and natural crossings, supporting the concept that staged crossing data can be a suitable alternative when natural pedestrian crossing data is difficult to obtain (such as when pedestrian volumes at a given location or time frame are low).

\subsection{Covariates and modifiers}

Several other factors were associated with increases in driver yielding rates, including high visibility crosswalk markings, crossings across fewer than three lanes, crossings on roads with posted speed limits of less than $30 \mathrm{MPH}$, and crossings in smaller municipalities (less than 60,000 in population). Speed has long been known to be a factor in pedestrian safety in general (Tefft, 2011). Thus, roadways with lower posted speed limits may be better candidates for pedestrian-related law enforcement unless additional measures are in place, such as traffic calming, to govern traffic speeds to the level needed for drivers to have sufficient detection and braking time. Shorter crossing distance, related to the number of traffic lanes, has also been associated with improved pedestrian safety (Federal Highway Administration, 2014). The fewer the lanes to cross, the simpler the crossing task for pedestrians; for drivers, fewer lanes of travel may make it may be easier to detect pedestrians waiting to cross. Similarly, high visibility crosswalk markings have known safety benefits and are often promoted in 
Table 6a

Differences in driver yielding rates by potential effect modifiers, observing staged crossings in 2013-2014 at 16 locations (standard and enhanced) in NC.

\begin{tabular}{|c|c|c|c|c|c|c|c|}
\hline \multirow[t]{2}{*}{ Covariate } & \multicolumn{3}{|c|}{ Standard Locations (Comparison) } & \multicolumn{3}{|c|}{ Enhanced Locations (Treated) } & \multirow{2}{*}{$\begin{array}{l}\text { Difference between Enhanced vs. } \\
\text { Standard Yield Rates Pre-Post } \\
\text { Differences }^{\mathrm{a}}\end{array}$} \\
\hline & $\begin{array}{l}\text { Pre-WFM } \\
\text { Yielding Rate }\end{array}$ & $\begin{array}{l}\text { Post-WFM } \\
\text { Yielding Rate }\end{array}$ & Difference & $\begin{array}{l}\text { Pre-WFM } \\
\text { Yielding Rate }\end{array}$ & $\begin{array}{l}\text { Post-WFM } \\
\text { Yielding Rate }\end{array}$ & Difference & \\
\hline \multicolumn{8}{|l|}{ City Population } \\
\hline$<60 \mathrm{~K}$ & $60.4 \%$ & $62.5 \%$ & $2.2 \%$ & $48.0 \%$ & $54.3 \%$ & $6.3 \%$ & $4.1 \%(1.0,7.9) p=0.01$ \\
\hline$>=60 \mathrm{~K}$ & $24.8 \%$ & $26.4 \%$ & $1.6 \%$ & $33.6 \%$ & $40.3 \%$ & $6.7 \%$ & $5.1 \%(-5.4,15.6) p=0.34$ \\
\hline \multicolumn{8}{|l|}{ Crossing Type } \\
\hline Uncontrolled Intersection & $25.1 \%$ & $26.3 \%$ & $1.2 \%$ & $35.3 \%$ & $42.1 \%$ & $6.8 \%$ & $5.6 \%(-6.0,17.2) p=0.35$ \\
\hline Midblock & $29.5 \%$ & $30.2 \%$ & $0.7 \%$ & $44.4 \%$ & $50.9 \%$ & $6.5 \%$ & $5.8 \%(-2.3,13.8), p=0.16$ \\
\hline \multicolumn{8}{|l|}{ Time of Day } \\
\hline Afternoon & $26.4 \%$ & $28.2 \%$ & $1.7 \%$ & $45.3 \%$ & $49.4 \%$ & $4.2 \%$ & $2.4 \%(-6.1,11.0), p=0.58$ \\
\hline Morning & $30.4 \%$ & $31.5 \%$ & $1.1 \%$ & $36.9 \%$ & $45.9 \%$ & $9.0 \%$ & $7.9 \%(-4.1,20.0) p=0.20$ \\
\hline \multicolumn{8}{|l|}{ Rush Hour } \\
\hline Peak & $19.2 \%$ & $22.9 \%$ & $3.8 \%$ & $39.1 \%$ & $48.7 \%$ & $9.7 \%$ & $5.9 \%(-2.2,14.0), p=0.15$ \\
\hline Off-peak & $38.3 \%$ & $39.1 \%$ & $0.8 \%$ & $42.7 \%$ & $46.5 \%$ & $3.8 \%$ & $3.0 \%(-4.5,10.6), p=0.43$ \\
\hline \multicolumn{8}{|l|}{ Crosswalk Marking Type } \\
\hline Standard & $39.4 \%$ & $43.0 \%$ & $3.6 \%$ & $40.3 \%$ & $42.9 \%$ & $2.6 \%$ & $-1.0 \%(-5.8,3.8), p=0.68$ \\
\hline High Visibility & $24.7 \%$ & $26.4 \%$ & $1.7 \%$ & $41.3 \%$ & $57.0 \%$ & $15.7 \%$ & $14.0 \%(7.6,20.4), p<0.01$ \\
\hline \multicolumn{8}{|l|}{ Speed Limit } \\
\hline$<30 \mathrm{MPH}$ & $34.7 \%$ & $37.0 \%$ & $2.3 \%$ & $43.2 \%$ & $53.8 \%$ & $10.7 \%$ & $8.4 \%(2.7,14.1), p<0.01$ \\
\hline $30 \mathrm{MPH}+$ & $23.6 \%$ & $25.6 \%$ & $2.0 \%$ & $35.4 \%$ & $36.5 \%$ & $1.2 \%$ & $-0.9 \%(-9.6,7.9), p=0.84$ \\
\hline \multicolumn{8}{|l|}{ Number of Lanes } \\
\hline 2 & $38.6 \%$ & $34.5 \%$ & $-4.1 \%$ & $42.8 \%$ & $47.2 \%$ & $4.5 \%$ & $8.6 \%(-2.2,19.4), p=0.12$ \\
\hline $3+$ & $17.9 \%$ & $21.2 \%$ & $3.4 \%$ & $36.5 \%$ & $48.7 \%$ & $12.2 \%$ & $8.9 \%(1.1,16.7), p=0.03$ \\
\hline \multicolumn{8}{|l|}{ Direction of Traffic } \\
\hline One-Way & $23.0 \%$ & $27.0 \%$ & $4.0 \%$ & $44.4 \%$ & $53.7 \%$ & $9.3 \%$ & $5.3 \%(-0.3,10.8), p=0.06$ \\
\hline Two-Way & $34.4 \%$ & $31.5 \%$ & $-2.9 \%$ & $40.1 \%$ & $46.6 \%$ & $6.5 \%$ & $9.4 \%(-0.9,19.7), p=0.07$ \\
\hline
\end{tabular}

a Based on a linear binomial GEE model with terms for treatment, time period, and interaction.

Table 6b

Differences in driver yielding rates by potential effect modifiers, observing naturalistic crossings in $2013-2014$ at 13 locations (standard and enhanced) in NC.

\begin{tabular}{|c|c|c|c|c|c|c|c|}
\hline \multirow[t]{2}{*}{ Covariate } & \multicolumn{3}{|c|}{ Standard Locations (Comparison) } & \multicolumn{3}{|c|}{ Enhanced Locations (Treated) } & \multirow{2}{*}{$\begin{array}{l}\text { Difference between Enhanced vs. } \\
\text { Standard Yield Rates Pre-Post } \\
\text { Differences }^{\mathrm{a}}\end{array}$} \\
\hline & $\begin{array}{l}\text { Pre-WFM } \\
\text { Yielding Rate }\end{array}$ & $\begin{array}{l}\text { Post-WFM } \\
\text { Yielding Rate }\end{array}$ & Difference & $\begin{array}{l}\text { Pre-WFM } \\
\text { Yielding Rate }\end{array}$ & $\begin{array}{l}\text { Post-WFM } \\
\text { Yielding Rate }\end{array}$ & Difference & \\
\hline City Population & & & & & & & \\
\hline $\begin{array}{l}<60 \mathrm{~K} \\
>=60 \mathrm{~K}\end{array}$ & $\begin{array}{l}70.6 \% \\
34.6 \%\end{array}$ & $\begin{array}{l}70.7 \% \\
36.9 \%\end{array}$ & $\begin{array}{l}0.1 \% \\
2.3 \%\end{array}$ & $\begin{array}{l}61.2 \% \\
43.3 \%\end{array}$ & $\begin{array}{l}66.5 \% \\
46.2 \%\end{array}$ & $\begin{array}{l}5.2 \% \\
2.9 \%\end{array}$ & $\begin{array}{l}5.1 \%(-2.3,12.5), p=0.17 \\
0.6 \%(-3.9,5.0), p=0.81\end{array}$ \\
\hline $\begin{array}{l}\text { Crossing Type } \\
\text { Uncontrolled Intersection } \\
\text { Midblock }\end{array}$ & $\begin{array}{l}41.0 \% \\
39.0 \%\end{array}$ & $\begin{array}{l}34.3 \% \\
42.3 \%\end{array}$ & $\begin{array}{l}-6.8 \% \\
3.3 \%\end{array}$ & $\begin{array}{l}45.4 \% \\
54.0 \%\end{array}$ & $\begin{array}{l}50.5 \% \\
57.7 \%\end{array}$ & $\begin{array}{l}5.2 \% \\
3.7 \%\end{array}$ & $\begin{array}{l}12.0 \%(9.7,14.2), p<0.01 \\
0.4 \%(-5.8,6.5), p=0.91\end{array}$ \\
\hline $\begin{array}{l}\text { Time of Day } \\
\text { Afternoon } \\
\text { Morning }\end{array}$ & $\begin{array}{l}30.6 \% \\
45.0 \%\end{array}$ & $\begin{array}{l}42.7 \% \\
40.4 \%\end{array}$ & $\begin{array}{l}12.1 \% \\
-4.6 \%\end{array}$ & $\begin{array}{l}46.5 \% \\
54.3 \%\end{array}$ & $\begin{array}{l}48.4 \% \\
60.1 \%\end{array}$ & $\begin{array}{l}1.9 \% \\
5.8 \%\end{array}$ & $\begin{array}{l}-10.1 \%(-22.4,2.2), p=0.11 \\
10.4 \%(4.4,16.3), p<0.01\end{array}$ \\
\hline $\begin{array}{l}\text { Rush Hour } \\
\text { Peak } \\
\text { Off-peak }\end{array}$ & $\begin{array}{l}32.4 \% \\
41.6 \%\end{array}$ & $\begin{array}{l}28.1 \% \\
44.9 \%\end{array}$ & $\begin{array}{l}-4.3 \% \\
3.3 \%\end{array}$ & $\begin{array}{l}56.4 \% \\
45.9 \%\end{array}$ & $\begin{array}{l}61.5 \% \\
48.3 \%\end{array}$ & $\begin{array}{l}5.1 \% \\
2.3 \%\end{array}$ & $\begin{array}{l}9.4 \%(5.8,13.0), p<0.01 \\
-1.0 \%(-9.0,7.0), p=0.81\end{array}$ \\
\hline $\begin{array}{l}\text { Crosswalk Marking Type } \\
\text { Standard } \\
\text { High Visibility }\end{array}$ & $\begin{array}{l}55.5 \% \\
33.4 \%\end{array}$ & $\begin{array}{l}52.8 \% \\
37.4 \%\end{array}$ & $\begin{array}{l}-2.8 \% \\
4.0 \%\end{array}$ & $\begin{array}{l}48.1 \% \\
59.3 \%\end{array}$ & $\begin{array}{l}52.8 \% \\
64.1 \%\end{array}$ & $\begin{array}{l}4.7 \% \\
4.8 \%\end{array}$ & $\begin{array}{l}7.4 \%(0.4,14.5), p=0.04 \\
0.8 \%(-4.9,6.5), p=0.78\end{array}$ \\
\hline $\begin{array}{l}\text { Speed Limit } \\
\text { <30 MPH } \\
30 \mathrm{MPH}+\end{array}$ & $\begin{array}{l}50.6 \% \\
33.1 \%\end{array}$ & $\begin{array}{l}51.3 \% \\
36.0 \%\end{array}$ & $\begin{array}{l}0.8 \% \\
2.9 \%\end{array}$ & $\begin{array}{l}60.5 \% \\
29.1 \%\end{array}$ & $\begin{array}{l}65.7 \% \\
32.8 \%\end{array}$ & $\begin{array}{l}5.2 \% \\
3.7 \%\end{array}$ & $\begin{array}{l}4.4 \%(-4.4,13.2), p=0.32 \\
0.8 \%(-1.4 .3 .0), p=0.50\end{array}$ \\
\hline $\begin{array}{l}\text { Number of Lanes } \\
2 \\
3+\end{array}$ & $\begin{array}{l}48.2 \% \\
27.3 \%\end{array}$ & $\begin{array}{l}49.3 \% \\
28.1 \%\end{array}$ & $\begin{array}{l}1.2 \% \\
0.8 \%\end{array}$ & $\begin{array}{l}48.4 \% \\
55.8 \%\end{array}$ & $\begin{array}{l}50.9 \% \\
64.8 \%\end{array}$ & $\begin{array}{l}2.5 \% \\
9.0 \%\end{array}$ & $\begin{array}{l}1.4 \%(-5.8,8.5), p=0.71 \\
8.2 \%(5.3,11.2), p<0.01\end{array}$ \\
\hline $\begin{array}{l}\text { Direction of Traffic } \\
\text { One-Way } \\
\text { Two-Way }\end{array}$ & $\begin{array}{l}33.1 \% \\
50.6 \%\end{array}$ & $\begin{array}{l}36.0 \% \\
51.3 \%\end{array}$ & $\begin{array}{l}2.9 \% \\
0.8 \%\end{array}$ & $\begin{array}{l}72.7 \% \\
46.9 \%\end{array}$ & $\begin{array}{l}76.2 \% \\
49.7 \%\end{array}$ & $\begin{array}{l}3.5 \% \\
2.9 \%\end{array}$ & $\begin{array}{l}0.6 \%(-1.3,2.5), p=0.54 \\
2.1 \%(-6.6,10.8), p=0.64\end{array}$ \\
\hline
\end{tabular}

a Based on a linear binomial GEE model with terms for treatment, time period, and interaction. 
relation to law enforcement efforts. For example, in the Gainesville, FL pedestrian safety program, existing crosswalk markings were refreshed and additional high-visibility markings were installed prior to an enforcement program (Van Houten et al., 2013b). The city size variable is most likely capturing a number of unmeasured factors associated with the different municipalities where data collection took place. Differences in population characteristics, driver or pedestrian "culture" or normative behaviors, traffic volumes, land use and roadway design that may influence driver and pedestrian behaviors, safety-related policies, and length of time that the community has emphasized pedestrian safety were all unmeasured variables that could potentially be attributed to the city size variable. That said, empirical experiences from involvement in the Watch for Me NC program delivery indicate that it was easier to reach "population saturation" with educational messages and enforcement activities in smaller, more closed communities given a fixed budget for program implementation, so city size may be an important modifier of program effects.

In our assessment of potential modifiers, we found that, for staged crossings events, presence of high visibility crosswalk markings was a modifier, while, for naturalistic crossings, location at an uncontrolled intersection (versus a midblock crossing) and the time of day were modifiers (more yielding observed in the morning compared to the afternoon). The importance of these effects is unclear, and it is unclear why modifiers would differ between naturalistic and staged crossings. It is plausible that the data collectors "staging" a crossing per the protocol needed the higher visibility markings to be detected by the drivers, as their behaviors approaching the crossing were less assertive than those of the "natural" pedestrians. It is also possible that modifiers may vary across locations depending on the context.

Interestingly, the relationship between driver yielding rates and Walk Score ${ }^{\circledR}$ at the crossing or city level varied across naturalistic and staged crossing types. Locations with better Walk Scores ${ }^{\circledR}$ were expected to have higher levels of pedestrian activity and by extension could be expected to have higher driver awareness and yielding to pedestrians. However, high Walk Score ${ }^{\circledR}$ locations also may be associated with higher levels of vehicle traffic due to the density of destinations and intersections, which may offset any increase in yielding behaviors. A drawback of a summary index such as Walk Score ${ }^{\circledR}$ is that it limits the ability to understand the separate effects of the built environment, such as land use and connectivity, which may affect driver yielding and pedestrian safety related outcomes in different ways.

\subsection{Study strengths and limitations}

The use of a pre-post design with treatment and comparison locations is a strength of this study. The pre-post design helped to control for fixed characteristics of the crossings (such as speed limit, number of lanes, etc.), while the use of a comparison group helped control for seasonal changes in driver behavior as well as vehicle and pedestrian volumes. In addition to conducting observations of real pedestrians, the study also used staged crossings to increase the available sample of vehicle-pedestrian interactions and standardize the pre-crossing actions of the pedestrians. In the study, most covariates did not change between the before and after period (city, direction, number of lanes, speed limit, crossing type, crosswalk marking type); those that were subject to change (such as the time of data collection) were controlled through the study design by keeping data collection times consistent at each location throughout the study. To the best of our knowledge, this is the first study of driver yielding that has used multivariate methods to explore the relationship between driver yielding and potential influences of roadway design features and identify potentially important covariates and effect modifiers. These data are impor- tant for the staff and decision-makers involved in pedestrian safety programs to gain a better understanding of the roadway design and behavioral mechanisms that could be used to improve driver yielding rates.

While we sought to adjust for numerous covariates through the design and analysis methods, as noted above, the potential for unmeasured confounders remains. The study was conducted in a real-world setting where it was not possible to randomize the crossings to standard or enhanced. Law enforcement may have unconsciously selected to "enhance" locations that had roadway features more conducive to the intervention effect, which would overstate the effect of the intervention. The research team members performing the "staged" crossings never collected data during times of active enforcement and were generally unaware of which locations were receiving enhanced enforcement; however, they could not be blinded to the engineering measures that were implemented at selected treated sites, and thus could have, theoretically, been influenced in their crossing behaviors over the course of the study. However, routine observations of the data collection team conducted throughout the study for quality control purposes did not detect changes in data collection techniques that could have significantly impacted the study results. The study was limited in the number of locations that could be included and by the amount of time available to monitor the locations before and after the Watch for Me NC program was delivered (6 months in total). The duration and frequency of enforcement needed to sustain longerterm changes are still not well-understood. Although only treated locations received enforcement and engineering improvements, both treatment and comparison locations had the potential to be affected by spill-over as a result of the media and outreach campaign that began prior to enforcement. Also, because the education component occurred before all enforcement and engineering improvements, it is not possible to know whether the effects observed would have occurred without this cueing.

Finally, more attention is needed to understand the relationship between the variables used in this study and how they relate to the ultimate safety outcome of reductions in crashes and injuries. Since pedestrian crashes are relatively rare events for any limited geographic area or short time period, the study relied on direct behavioral measures of driver yielding as a more appropriate outcome measure for evaluating the impact of the intervention in changing behaviors that can lead to crash prevention. We acknowledge that the relationship between driver yielding and crashes may be complex and non-linear, and that improvements in driver yielding may not translate into tangible reductions in pedestrian crashes. Future studies are needed to examine additional pedestrian safety outcomes, such as changes in pedestrian crash rates, and to monitor the longer term safety impacts of comprehensive interventions.

\subsection{Conclusion}

The results of this effort provide evidence of positive increases in driver yielding rates associated with the Watch for Me NC intervention. This information can aid decision-makers at both the state and local level in understanding the potential effectiveness of pedestrian safety interventions such as the Watch for Me NC program.

\section{Acknowledgements}

Portions of this study were funded by the National Highway Traffic Safety Administration (contracting officer: Leah Walton) and the North Carolina Department of Transportation (contracting officer: Lauren Blackburn). Many current and former HSRC staff contributed to the Watch for Me NC intervention development, implementation, and evaluation, including Nancy Pullen-Seufert, 
James Gallagher, Seth LaJeunesse, Max Bushell, Dan Gelinne, Rob Foss, Laura Wagner, Charlie Zegeer, and Libby Thomas. Credit goes to former HSRC staff Nelson Holden, Artur Khalikov, Matt Evans, Marissa Miano, Madison Savage, and Bryan Poole for their role in field data collection and entry. Dr. Marshall is partly supported by a grant R49-CE002479 from the Centers for Disease Control and Prevention in support of the UNC Injury Prevention Research Center.

\section{References}

Centers for Disease Control and Prevention (CDC), 2009. CDC Injury Research Agenda: 2009-2018. U.S. Department of Health and Human Services, Centers for Disease Control and Prevention, National Center for Injury Prevention and Control, Atlanta, Georgia, pp. 66, Retrieved June 28, 2013 from http://www. cdc.gov/injury/researchagenda/cdc_injury_research_agenda-a.pdf.

Federal Highway Administration, 2014. Pedestrian Safety Guide and Countermeasure Selection System. Washington, DC. Retrieved from http:// pedbikesafe.org/PEDSAFE/index.cfm on August 16, 2015.

Finkelstein, E., Corso, P., Miller, T., 2006. Incidence and economic burden of injuries in the United States, 2000. Journal of Epidemiology and Community Health. Oxford University Press, New York, NY.

Hirsch, J.A., Moore, K.A., Evenson, K.R., Rodriguez, D.A., Diez Roux, A.V., 2013. Walk scores and transit scores and walking in the multi-ethnic study of atherosclerosis. Am. J. Prev. Med. 45 (2), 158-166.

National Highway Traffic Safety Administration, 2014. Traffic Safety Facts: Pedestrians. Retrieved from http://www-nrd.nhtsa.dot.gov/Pubs/811888.pdf.

Nee, J., Hallenbeck, M.E., 2003. A Motorist And Pedestrian Behavioral Analysis Relating To Pedestrian Safety Improvements, Final Report, Research Project T1803, Task 16. Washington State Transportation Center (TRAC), Retrieved
January 7, 2013: http://www.wsdot.wa.gov/research/reports/fullreports/560. 1.pdf.

Sandt, L., Gallagher, J., Pullen-Seufert, N., Poole, B., 2014. Bicycle and Pedestrian Safety, Education, and Enforcement Campaign: Project Summary and Evaluation, Final Report, Contract \#MA-2009-07. North Carolina Department of Transportation (NCDOT), Retrieved March 16, 2016: http://www. watchformenc.org/wp-content/themes/WatchForMeNC_Custom/documents/ WFM_Final\%20Report.pdf.

Sandt, L., Marshall, S.W., Ennett, S.T., 2015. Community-based pedestrian and bicycle safety program: developmental framework and process evaluation. Transportation Research Record 2519: Journal of the Transportation Research Board. Washington, DC. pp 51-60.

Stokes, M.E., Davis, C.S., Koch, G.G., 2000. Categorical Data Analysis Using the SAS System, second ed. SAS Institute Inc, Cary, NC.

Tefft, B.C., 2011. Impact Speed and a Pedestrian's Risk of Severe Injury or Death. AAA Foundation for Traffic Safety, Washington, DC, Retrieved from https:// www.aaafoundation.org/sites/default/files/2011PedestrianRiskVsSpeed.pdf on August 16, 2015.

University of North Carolina, 2011. North Carolina Pedestrian Crash Facts 2005-2009. UNC Highway Safety Research Center, Chapel Hill, NC http://www ncdot.gov/bikeped/download/summary_ped_facts05-09.pdf.

Van Houten, R., Malenfant, J.E.L., 2004. Effects of a driver enforcement program on yielding to pedestrians. J. Appl. Behav. Anal. 37, 351-363.

Van Houten, R., Malenfant, L., Huitema, B., Blomberg, R., 2013. The Effects of High Visibility Enforcement on Driver Compliance to Pedestrian Yield Right-of-Way Laws. Transportation Research Record 2093: Journal of the Transportation Research Board. Washington, DC. pp. 41-49.

Van Houten, R., Malenfant, L., Blomberg, R.D., Huitema, B.E., Casella, S., 2013b. High-Visibility Enforcement on Driver Compliance With Pedestrian Right-of-Way Laws. (Report No. DOT HS 811 786). National Highway Traffic Safety Administration, Washington, DC. 